\title{
An Electron-microscopic Examination of Certain Bovine Mycoplasmas Stained with Ruthenium Red and the Demonstration of a Capsule on Mycoplasma dispar
}

\author{
By C. J. HOWARD AND R. N. GOURLAY \\ Agricultural Research Council, Institute for Research in Animal Diseases, Compton, \\ Newbury, Berkshire RGI6 oNN
}

(Received I8 March 1974)

SUMMARY

Mycoplasmadispar has been shown to produce a capsule which can be visualized by electron microscopy following staining with ruthenium red. The capsule of $M$. dispar possesses no obvious structure and extends for 17 to $24 \mathrm{~nm}$ beyond the cytoplasmic membrane. Ruthenium red also stains the capsule of $M$. mycoides var. mycoides so that it can be seen by electron microscopy. Five other bovine mycoplasmas, M. agalactiae var. bovis, M. bovigenitalium, M. bovirhinis, Acholeplasma laidlawii and a T-mycoplasma, and one human mycoplasma, $M$. pneumoniae, were found not to produce a capsule.

\section{INTRODUCTION}

Springer \& Roth (1973) used Luft's (197I) staining procedure with ruthenium red to visualize the capsules of Diplococcus pneumoniae and Klebsiella pneumoniae by electron microscopy. Their observations prompted us to use this technique to determine whether certain bovine mycoplasmas produce capsules. As Mycoplasma mycoides var. mycoides is known to produce a capsule apparently composed largely of galactan (Gourlay \& Thrower, 1968), this micro-organism was included in our study as a positive control.

Since mycoplasmas do not synthesize a cell wall, the cytoplasmic membrane is usually considered to be that part of the organism in direct contact with the environment. The term capsule is used here to describe the material present outside the mycoplasma membrane.

\section{METHODS}

Media. The T-mycoplasma strain was grown in U2 broth (Howard \& Gourlay, 1973a). All other mycoplasmas were grown in glucose calf-serum broth (Gourlay \& Leach, 1970) in which ampicillin (Beecham Research Laboratories, Brentford), I $\mathrm{mg} / \mathrm{ml}$, had been substituted for benzylpenicillin (Andrews, Leach, Gourlay \& Howard, 1973). All media were filtered (220 nm Millipore filters) before inoculation.

Mycoplasma strains. Mycoplasma dispar strains F370, vic 2 and Gri22I were isolated from pneumonic calf lungs, and purified by filtration of broth cultures $(650 \mathrm{~nm}$ Millipore filters) and by picking single colonies on three successive occasions (Subcommittee on the Taxonomy of Mycoplasmatales, 1972). Mycoplasma mycoides var. mycoides T2 vaccine strain and strain KH3J have been described previously (Gourlay \& Thrower, I968). Mycoplasma bovirhinis strain oIOC was isolated from the eye of a cow with keratoconjunctivitis and purified as for the $M$. dispar strains except that a $450 \mathrm{~nm}$ Millipore filter was used. I-mycoplasma strain A4I7 has been described previously (Howard \& Gourlay, 1973 b). tcholeplasma laidlawii strain Mr305/68, M. agalactiae var. bovis strains NCTCror3I and 
M720/70, and $M$. bovigentalium strains $M 338 / 70$ and M991/70 were obtained from Dr R. H. Leach (Mycoplasma Reference Laboratory, Colindale, London). M. pneumoniae strain NCTCIOII9 and $M$. bovirhinis strain PG 43 (NCTCIOII8) were obtained from the National Collection of Type Cultures, Colindale, London. Mycoplasma bovirhinis strain CI55 was isolated originally from a case of pneumo-enteritus and was provided by Dr Carmichael (Langer \& Carmichael, 1963). It was purified as for strain oroc.

Electron microscopy. Mycoplasma strains were harvested by centrifugation at $15000 \mathrm{~g}$ for $30 \mathrm{~min}$. Pellets were suspended in a mixture of equal volumes of $3.6 \%(\mathrm{w} / \mathrm{v})$ glutaraldehyde, $0.2 \mathrm{M}$-cacodylate buffer, $\mathrm{pH} 5.5$, and ruthenium red $\left(\mathrm{I} \cdot 5 \mathrm{mg} / \mathrm{ml} \mathrm{H}_{2} \mathrm{O}\right.$ ), for $\mathrm{I} \mathrm{h}$ at $4{ }^{\circ} \mathrm{C}$. After three washings with cacodylate buffer the mycoplasmas were post-fixed by adding a mixture of $4 \%(\mathrm{w} / \mathrm{v})$ osmium tetroxide, $0.2 \mathrm{M}$-cacodylate buffer, $\mathrm{pH} 6.5$, and ruthenium red $\left(\mathrm{I} .5 \mathrm{mg} / \mathrm{ml} \mathrm{H}_{2} \mathrm{O}\right.$ ), and incubating for $2 \mathrm{~h}$ at $20{ }^{\circ} \mathrm{C}$ (Springer \& Roth, 1973). Samples were dehydrated by suspension in 50 and $75 \%(\mathrm{v} / \mathrm{v})$ ethanol, each for $5 \mathrm{~min}$ at $20{ }^{\circ} \mathrm{C}$, followed by two washings with absolute ethanol for $30 \mathrm{~min}$ at $20^{\circ} \mathrm{C}$. They were next transferred to epoxy propane and embedded in Araldite. Sections 50 to $60 \mathrm{~nm}$ thick were cut using glass knives on a Reichert model OMU 2 ultramicrotome, and were examined with a Philips EM 300 microscope using an accelerating voltage of $80 \mathrm{kV}$.

Samples not stained with ruthenium red were fixed in phosphate buffered glutaraldehyde (Sabatini, Bensch \& Barrnett, 1963) for $2 \mathrm{~h}$ at $4{ }^{\circ} \mathrm{C}$, washed with phosphate buffer, $\mathrm{pH} 7 \cdot 3$, for $4 \mathrm{~h}$ at $4{ }^{\circ} \mathrm{C}$, post-fixed in osmium fixative (Millonig, I96I) for $\mathrm{I} \mathrm{h}$ at $4{ }^{\circ} \mathrm{C}$, dehydrated and embedded as before, and stained with uranyl acetate followed by lead citrate (Venable \& Coggeshall, I965).

\section{RESULTS}

Mycoplasma mycoides var. mycoides. A capsule was seen by electron microscopy in preparations of strain T2 following ruthenium red treatment (Fig. I). This capsule does not appear to possess any obvious structure and becomes more diffuse as distance from the cytoplasmic membrane increases. In strain $\mathrm{T} 2$ the capsule extends about $30 \mathrm{~nm}$ from the membrane. No capsular material was seen in strain KHзJ.

Mycoplasma dispar. Figures 3, 4 and 5 show the result of staining with ruthenium red. All three isolates possess material which extends for 17 to $24 \mathrm{~nm}$ outside the membrane. This capsular material stains less intensely than that of $M$. mycoides var. mycoides, but as with $M$. mycoides var. mycoides no obvious structure is evident and it becomes more diffuse as distance from the membrane increases. When $M$. dispar that had not been treated with ruthenium red was examined by electron microscopy a small amount of material was evident outside the membrane (Gourlay \& Leach, 1970). However, this material does not seem to be the same as that seen following ruthenium red treatment as it has different dimensions and staining properties.

Other mycoplasmas. None of the other mycoplasmas examined possessed any structure equivalent to the capsule of $M$. ciispar and $M$. mycoides var. mycoides. When $A$. laidlawii strain MI305/68 was stained with ruthenium red (Fig. 6), no extramembranous material was evident, nor was any observed on $M$. bovirhinis strains PG43, O IOC, CI 55 or T-mycoplasma strain A4I7. Mycoplasma bovigenitalium strains M991/70 and M338/70 (Fig. 7) and $M$. agalactiae var. bovis strains NCTC $\mathrm{OI}_{3} \mathrm{I}$ and M720/70 (Fig. 8) appeared to have some material outside the membrane of about the same dimensions as the membrane. However, they did not possess a definite capsule equivalent to that of $M$. dispar.

Mycoplasma pneumoniae strain NCTCIOr 19, examined because of its importance in human disease, did not appear to possess a similar capsule. 

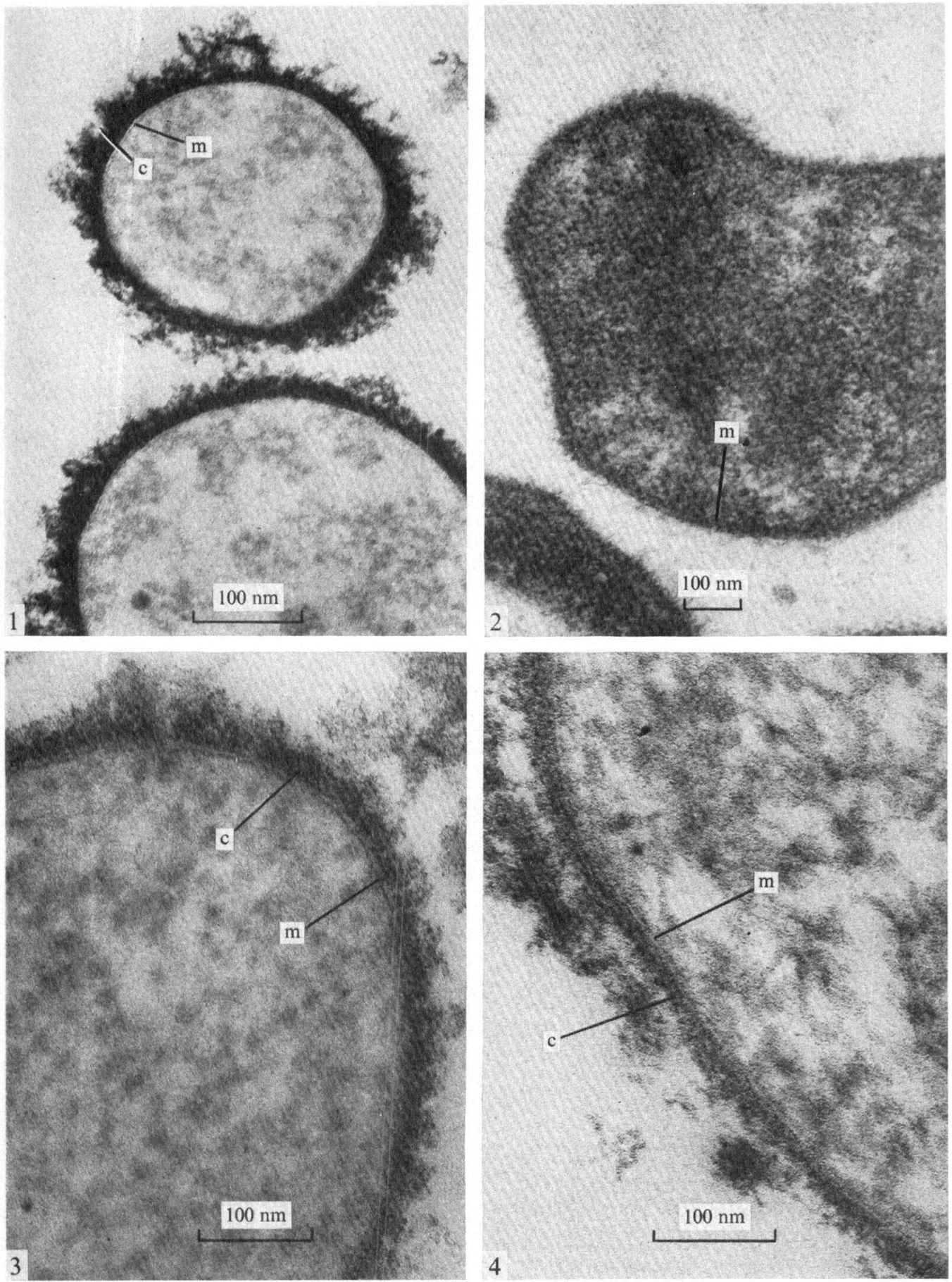

Fig. 1. Mycoplasma mycoides var. mycoides strain T2 stained with ruthenium red. Capsular material (c) is evident outside the membrane $(\mathrm{m})$.

Fig. 2. Mycoplasma dispar strain vicı 2 stained with uranyl acetate. No capsular material is present outside the membrane (m).

Fig. 3. Mycoplasma dispar strain Griz2 I stained with ruthenium red. Capsular material (c) can be seen outside the membrane $(\mathrm{m})$.

Fig. 4. Mycoplasma dispar strain F370 stained with ruthenium red. Capsular material (c) is evident outside the membrane $(\mathrm{m})$. 

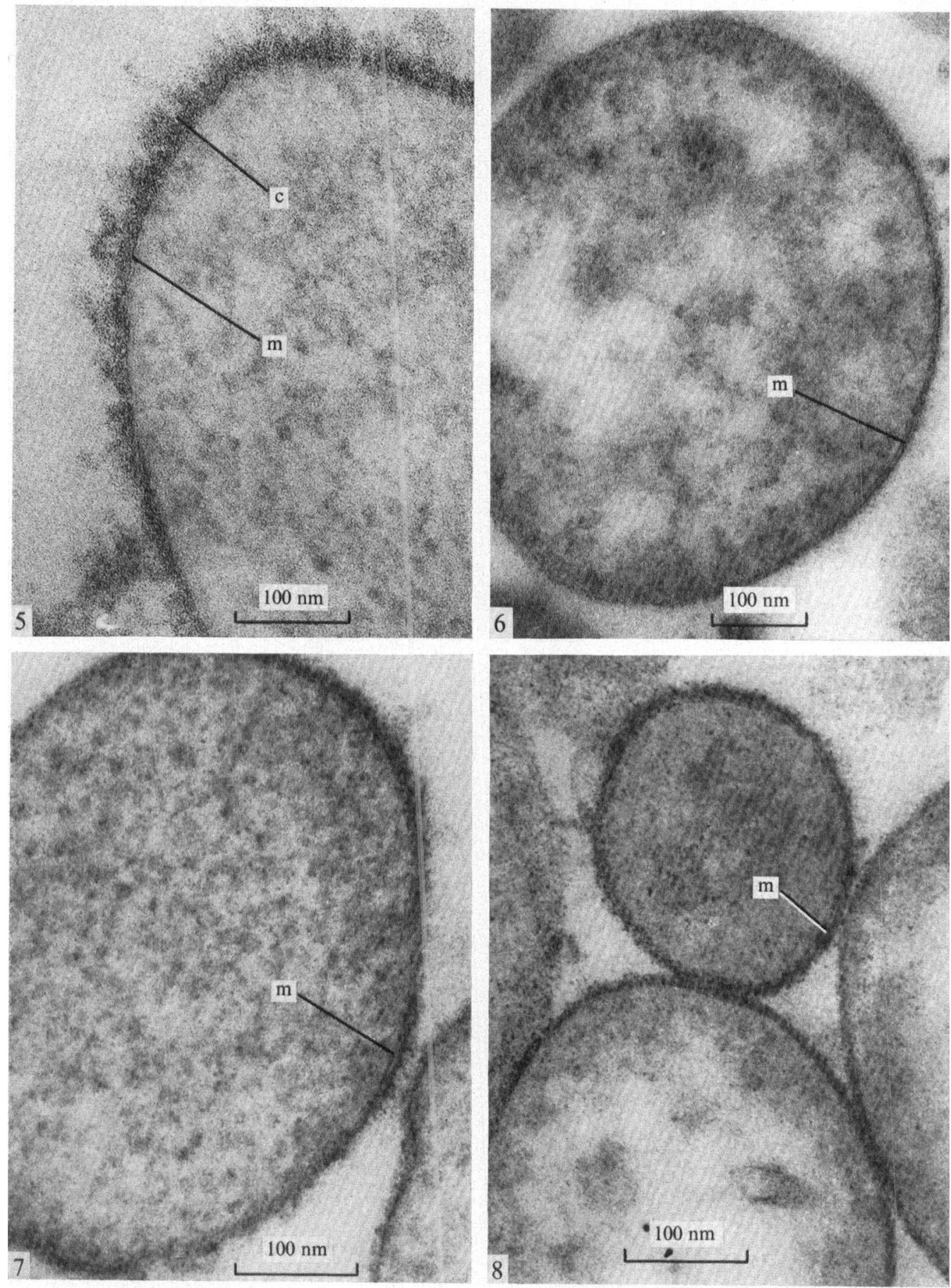

Fig. 5. Mycoplasma dispar strain vic 2 stained with ruthenium red. Capsular material (c) is evident outside the membrane $(\mathrm{m})$.

Fig. 6. Acholeplasma laidlawii strain mI305/63 stained with ruthenium red. No capsule is evident.

Fig. 7. Mycoplasma bovigenitalium strain $\mathrm{M} 33 / 70$ stained with ruthenium red. No capsule is evident but some amorphous material is present outsite the membrane $(\mathrm{m})$.

Fig. 8. Mycoplasma agalactiae var. bovis strain $\mathrm{m} 720 / 70$ stained with ruthenium red. No capsule is evident but some amorphous material is present outside the membrane $(\mathrm{m})$. 


\section{DISCUSSION}

Mycoplasma mycoides var. mycoides is known to produce a capsule (Gourlay \& Thrower, I968), apparently composed of galactan (Buttery \& Plackett, I960); more recently Green \& Hanson (I973) demonstrated the presence of a capsule in $M$. meleagridis, following precipitation with antiserum and staining with ruthenium red.

Amongst the bovine mycoplasmas we have studied, both $M$. mycoides var. mycoides $\mathrm{T} 2$ and all three $M$. dispar strains have been shown to possess capsules that can be visualized by electron microscopy following staining with ruthenium red. Mycoplasma mycoides var. mycoides strain KH3J, on which no capsular material was observed, is also known to be avirulent and not to produce threads (Gourlay \& Thrower, 1968).

No material equivalent to the capsule of $M$. mycoides var. mycoides and $M$. dispar was observed on any of the isolates representing $M$. bovirhinis, T-mycoplasmas, A. laidlawii and $M$. pneumoniae. However, $M$. agalactiae var. bovis and $M$. bovigenitalium stained with ruthenium red can be seen to have some material outside the membrane, but so do many other mycoplasmas, including $M$. agalactiae when examined by electron microscopy without ruthenium red treatment (Domermuth, Nielsen, Freundt \& Birch-Andersen, 1964). No structure equivalent to the capsule of $M$. mycoides var. mycoides and $M$. dispar was observed in these two species.

The capsule of $M$. mycoides var. mycoides strain T2 is not seen by electron microscopy if specimens are not treated with ruthenium red (Gourlay \& Thrower, I968), and although Gourlay \& Leach (1970) observed a fringe of amorphous material outside the membrane of $M$. dispar that had not been treated with ruthenium red, the dimensions of this fringe were such as to indicate this material was not identical to the capsule seen following ruthenium red treatment. However, the material seen beyond the plasma membrane of $M$. dispar not treated with ruthenium red could be the inner layer of the capsule seen when the organism is treated with ruthenium red. The outer layers may be less tightly bound and lost during processing unless treated with ruthenium red. Alternatively, the capsular material may only react with ruthenium red and not be stained by the other method involving osmium tetroxide, uranyl acetate and lead citrate. Capsules rendered visible by electron microscopy following ruthenium red treatment do not seem to be a common finding amongst bovine mycoplasmas.

The ultrastructure of the $M$. mycoides var. mycoides and the $M$. dispar capsule appear similar. Neither possesses any clear structure and seem to become less dense as distance from the membrane increases. However, the capsular material of M. mycoides var. mycoides stains more intensely than that of $M$. dispar. The appearance of the capsule of $M$. meleagridis (Green \& Hanson, 1973) is similar to these other two mycoplasma capsules. The ultrastructure of the mycoplasma capsule is distinct from those of $D$. pneumoniae, where the capsule was found to have a fibrous structure, and K. pneumoniae where a spike- or net-like appearance was observed (Springer \& Roth, 1973).

Luft ( 1971) studied the interaction of ruthenium red with various compounds. He stated that ruthenium red reacted most strongly with substances possessing a high negative charge density and a high molecular weight. Ruthenium red was capable of precipitating a large number of polyanions, e.g. phospholipids, acid polysaccharides, mucopolysaccharides, and fatty acids. Since ruthenium red does not react specifically with any group of chemical compounds, definite conclusions on the chemical nature of the $M$. dispar capsule cannot be made.

Many instances are known of capsular material being important in determining the virulence of bacteria (MacLeod, 1958), and the amount of galactan capsule produced by 
strains of $M$. mycoides var. mycoides nay be related to virulence (Gourlay \& Thrower, 1968). Although the significance of the capsule of $M$. dispar is unkonwn it is potentially an important factor enabling strains to evade host defence mechanisms, a property often attributed to capsular material (MacLecd, 1958; Meynell, 196 I; Glynn, 1972).

We thank Mrs P. Bland and Mr B. France for the electron micrographs, and Mrs J. Collins, Miss E. Coleman and Miss S. G. Wyld for their excellent technical assistance.

\section{REFERENCES}

Andrews, B. E., Leach, R. H., Gourlay, R. N. \& Howard, C. J. (I973). Enhanced isolation of Mycoplasma dispar by substitution of ampicillin for benzylpenicillin in growth media. Veterinary Record $\mathbf{9 3}$, 603 .

Buttery, S. H. \& Plackett, P. (1960). A specific polysaccharide from Mycoplasma mycoides. Journal of General Microbiology 23, 357-368.

Domermuth, C. H., Nielsen, M. H., Freunit, E. A. \& Birch-Andersen, A. (ig64). Ultrastructure of Mycoplasma species. Journal of Bacteriolo; $; y$ 88, 727-744.

GLYNN, A. A. (1972). Bacterial factors inhibiting host defence mechanisms. Symposia of the Society for General Microbiology 22, 75-1 I 2.

Gourlay, R. N. \& LeACH, R. H. (1970). A new mycoplasma species isolated from pneumonic lungs of calves (Mycoplasma dispar sp. nov.). Journal of Medical Microbiology 3, 11 1-123.

Gourlay, R. N. \& Tirrower, K. J. (I968). Morphology of Mycoplasma mycoides thread-phase growth. Journal of General Microbiology 54, I $55^{-1} 59$.

Green, F. \& HANSON, R. P. (1973). Ultrast cucture and capsule of Mycoplasma meleagridis. Journal of Bacteriology I16, $1011-1018$.

HowARD, C. J. \& GourLAY, R. N. (1973a). Inhibition by normal rabbit sera of the growth of T-mycoplasma strains isolated from different animal species. Journal of General Microbiology 78, 277-285.

Howard, C. J. \& Gourlay, R. N. (1973 b). Serological comparison of bovine T-mycoplasmas. Journal of General Microbiology 79, I29-134.

LANGER, P. H. \& CARMichafL, L. E. (1963). Identification of pneumoenteritis isolates from cattle as mycoplasma. In Proceedings of the 67th Meeting of the U.S. Livestock Sanitary Association, pp. I29-1 37.

LufT, J. H. (1971). Ruthenium red and violet. I. Chemistry, purification, methods of use for electron microscopy and mechanism of action. Anatomical Record $\mathbf{1 7}$ 1, 347-368.

MACLEOD, C. M. (1958). Pathogenic propertic's of bacteria and defence mechanisms of the host. In Bacterial and Mycotic Infections of Man, 3rd edn., pp. 83-1 I 3. Edited by R. J. Dubos. London: Pitman Medical.

Meynell, G. G. (196I). Phenotypic variation and bacterial infection. Symposia of the Society for General Microbiology II, 174-195.

MilloniG, G. (1961). Advantage of a phosphate buffer for osmium tetroxide solutions in fixation. Journal of Applied Physics 32, I637.

Sabatini, D. D., Bensch, K. \& Barrnett, R. J. (1963). Cytochemistry and electron microscopy. The preservation of cellular ultrastructure and e zzymatic activity by aldehyde fixation. Journal of Cell Biology 17, $19-58$.

SPringer, E. L. \& Roth, I. L. (1973). The iltrastructure of the capsules of Diplococcus pneumoniae and Klebsiella pneumoniae stained with ruthenium red. Journal of General Microbiology 74, 21-3I .

SubCommittee on the TAXoNomy of Mycopl asmatales (1972). Proposal for minimal standards for description of new species of the order Mycoplasmatales. International Journal of Systematic Bacteriology 22, $184-188$.

Venable, J. H. \& Coggeshall, R. (I965). A simplified lead citrate stain for use in electron microscopy. Journal of Cell Biology 25, 407-408. 